\title{
Comparative Free Radical Scavenging Activity of Seed Coat Extracts from Caesalpinia pulcherrima and Delonix regia
}

\author{
Wancheng Sittikijyothin $^{1, \mathrm{a}}$, Wasana Sasein ${ }^{2, \mathrm{~b}}$, Patcharaporn Rumpai ${ }^{2, \mathrm{c}}$, Duangrudee Cherdwongcharoensuk ${ }^{2, \mathrm{~d}}$ \\ ${ }^{1}$ Department of Chemical Engineering, Faculty of Engineering, Burapha University, Chonburi, 20131 Thailand \\ ${ }^{2}$ Faculty of Allied Health Sciences, Burapha University, Chonburi, 20131 Thailand \\ awancheng@buu.ac.th, ${ }^{\mathrm{b}, \mathrm{c}}$ pr_patcha@hotmail.com, duangrudd@hotmail.com
}

\begin{abstract}
Caesalpinia pulcherrima and Delonix regia are generally grown in Thailand and used in traditional medicine having medicinal therapeutic effects. The antioxidant ability of seed extract has been presented by few investigators whereas no data has been reported the different antioxidant activity between embryo, endosperm and seed coat extracts from both species. Difference types of tissues and varieties may cause a difference seed contents and antioxidant characters. Hence, the main aim of this study is to compare the free radical scavenging activity of embryo, endosperm and seed coat extracts between C. pulcherrima and D. regia. It was found that the phenolic compounds found in embryo extract (100, 200,400 and $1,000 \mu \mathrm{g} / \mathrm{ml}$ ) of C. pulcherrima (16 to $238 \mu \mathrm{g}$ gallic acid equivalents) and $D$. regia (33 to $379 \mu$ g gallic acid equivalents) were significantly higher than those of endosperm and seed coat extracts. The percentage of DPPH scavenging activity of seed coat extracts of C. pulcherrima (8.68 to 76.16 ) and D. Regia (2.69 to $9.63)$ were higher than those of endosperm and embryo extracts. In addition, the percentage of DPPH scavenging activity of seed coat extracts of $C$. pulcherrima was statistically significant higher than $D$. regia. Finally, we can conclude that (1) the highest phenolic contents were found in embryo extract, (2) the seed coat extract of $C$. pulcherrima had the highest antioxidant activity (3) phenolic contents and antioxidant activity of seed coat extracts of $C$. pulcherrima were significantly higher than D. regia, and (4) the total contents of phenolic compounds and the percent DPPH scavenging activity were depended on types of tissues and species.
\end{abstract}

Index Terms - Antioxidant, Phenolic compound, Caesalpinia pulcherrima, Delonix regia

\section{Introduction}

Free radicals species are atoms, molecules, or ions with unpaired electrons on an open shell configuration causing and adverse health effects, such as, cancer, atherosclerosis, Alzheimer's disease, tumour, leukaemia and malignant neoplasia [1]. Since the costs of medicines and treatments are extremely high and the side effects also occur frequently during medical care or treatments. A medicinal herb has extensively been chosen as a natural anti-free radical species or anti-oxidant in the traditional medicine for patients suffering from diseases. The phenolic compounds in medicinal herbs showing an antioxidant properties act as reducing agents, hydrogen donors, free radical quenchers and metal chelators. Furthermore, antioxidants have an ability to protect tissue damage caused by free radical induced by oxidative stress [1].
Caesalpinia pulcherrima and Delonix regia are generally grown in Thailand and used in traditional medicine having the antioxidant activities reported by various investigators. $D$. regia contains lupeol, epilupeol, $\beta$-sitosterol, stigmasterol and p-methoxybenzaldehyde in the extracts of stems bark and leaves having antimicrobial and anti-inflammatory activities $[2,3]$. The extraction of aerial parts and dry fruits of $C$. pulcherrima exhibits antimicrobial, antiviral, antiinflammatory and antiulcer activities [4-6]. However, there are no data reported the different antioxidant activity between embryo, endosperm and seed coat extracts from $C$. pulcherrima and $D$. regia. So the aim of this study is to compare the phenolic contents and free radical scavenging activity from different parts of C. pulcherrima and D. regia.

\section{Materials and Methods}

Materials. Seeds of C. pulcherrima and D. regia were obtained from Chonburi province in Thailand.

Reagents. All reagents were obtained from either Sigma-Aldrich or Cayman: L-ascorbic acid, 1, 1-Diphenyl-2picrylhydrazyl (DPPH), Folin Ciocalteu's phenol reagent, Sodium carbonate and Absolute ethanol.

Extraction Preparation. Seed coats, endosperms and embryos of C. pulcherrima's and D. regia's seeds were kept and dried in the oven at $38^{\circ} \mathrm{C}$ for 3 days. Then, all three separated parts of both seeds were mashed, sifted and kept in desiccator.

Powder of seed coats, endosperms and embryos $10 \mathrm{~g}$ were extracted with absolute ethanol $50 \mathrm{ml}$ and stirred with shaker 1 hour. The supernatant was filtrated and evaporated by rotary evaporator. The viscous crude extract was diluted with absolute ethanol $10 \mathrm{ml}$ and the divide into 10 parts. Each part containing the crude extract from $1 \mathrm{~g}$ of sample's powder was evaporated by rotary evaporator and then dissolved in water or absolute ethanol used for determination of total phenolic compounds and antioxidant activity.

Determination of Total Phenolic Compounds. The total phenolic compounds in seed coats, endosperms and embryos of C. pulcherrima's and D. regia's seeds were determined with Folin-Ciocalteu reagent according to the method of Slinkard and Singleton (1997) [7] using gallic acid as a standard phenolic compound. Briefly, $0.5 \mathrm{ml}$ of the extract from 100, 200, 400 and $1000 \mu \mathrm{g}$ of sample per $\mathrm{ml}$ 
$(\mu \mathrm{g} / \mathrm{ml})$, distilled water $(0.5 \mathrm{ml})$ and Folin-Ciocalteu reagent $(0.5 \mathrm{ml})$ were mixed. After $5 \mathrm{~min}, 2 \mathrm{ml}$ of $\mathrm{Na}_{2} \mathrm{CO}_{3}(10 \%)$ was added, and then the mixture was allowed to stand for $10 \mathrm{~min}$ with intermittent shaking. The absorbance was measured at $760 \mathrm{~nm}$. This experiment was repeated three times. The total phenolic compounds of extract were determined in micrograms $(\mu \mathrm{g})$ of gallic acid equivalents, using the equation obtained from the standard curve of gallic acid graph.

Determination of DPPH Radical Scavenging Activity. DPPH radical scavenging activity was performed according to the method of Blios (1958) [8] with a minor modification, using ascorbic acid as a standard solution. The odd electron in DPPH radical gives a strong absorption maximum at $517 \mathrm{~nm}$ and radical colour is purple. Briefly, $1.5 \mathrm{ml}$ of the extract from $100,200,400$ and $1,000 \mu \mathrm{g}$ of sample per $\mathrm{ml}(\mu \mathrm{g} / \mathrm{ml}), 1.5 \mathrm{ml}$ of $0.1 \mathrm{M}$ DPPH radical solution in absolute ethanol were mixed and kept for 30 min at room temperature in the dark. Disappearance of DPPH radical colour upon radical reduction was monitored by measuring the absorbance at $517 \mathrm{~nm}$. This experiment was repeated three times. Percentage of DPPH scavenging was calculated according to the following equation:

\section{$\%$ DPPH scavenging $=$}

(A absorbance of control - A absorbance of sample) x 100

An absorbance of control
Statistic Analysis. All results are expressed as mean \pm standard deviation (SD), and the difference between groups was performed using one-way ANOVA (single factor). Significance was accepted at the $\mathrm{P}<0.005$ levels.

\section{Results and Discussion}

Total phenolic contents. The total phenolic content of the extract were determined in micrograms of gallic acid equivalents, using the equation obtained from the linear regression equation of standard curve of gallic acid graph ( $\mathrm{Y}$ $=0.001 \mathrm{x}-0.008, \mathrm{R}^{2}=0.999$ ) (not shown). Where $\mathrm{Y}$ is gallic acid equivalents $(\mu \mathrm{g})$ and $\mathrm{X}$ is the absorbance.

In the table 1, the phenolic compounds found in embryo extract $(100-1000 \mu \mathrm{g} / \mathrm{ml})$ of C. pulcherrima (16 to $238 \mu \mathrm{g}$ gallic acid equivalents) and $D$. regia (33 to $379 \mu \mathrm{g}$ gallic acid equivalents) were significantly higher than those of endosperm and seed coat extracts. In addition, phenolic contents in embryo and endosperm extract of $D$. regia were statistically significant higher than C. pulcherrima. In contrast, seed coat extract of $D$. regia contained phenolic contents was significant less than C. rulcherrima. In addition, the total amount of phenolic compound was commonly increased corresponded to the concentrations of the extracts.

Table 1 Total phenolic contents of embryo, endosperm and seed coat extracts of Caesalpinia pulcherrima and Delonix regia

\begin{tabular}{|c|c|c|c|c|c|c|}
\hline \multirow{2}{*}{ Conc. $(\mu \mathrm{g} / \mathrm{ml})$} & \multicolumn{3}{|c|}{ Caesalpinia pulcherrima $(\mu \mathrm{g}$ of gallic acid) } & \multicolumn{3}{c|}{ Delonix regia $(\mu \mathrm{g}$ of gallic acid) } \\
\cline { 2 - 7 } & Embryo & Endosperm & Seed coat & Embryo & Endosperm & Seed coat \\
\hline 100 & $16.00 \pm 5.00$ & $7.33 \pm 6.03$ & $20.67 \pm 8.33$ & $33.00 \pm 5.29$ & $6.00 \pm 2.65$ & $6.00 \pm 4.36$ \\
\hline 200 & $42.67 \pm 4.51$ & $10.33 \pm 6.35$ & $36.00 \pm 6.25$ & $64.00 \pm 6.08$ & $6.67 \pm 5.03$ & $9.33 \pm 3.06$ \\
\hline 400 & $71.33 \pm 1.53$ & $10.67 \pm 5.86$ & $52.67 \pm 3.22$ & $126.00 \pm 6.08$ & $8.00 \pm 2.00$ & $10.33 \pm 4.51$ \\
\hline 1,000 & $238.00 \pm 1.38$ & $13.67 \pm 2.08$ & $138.67 \pm 23.16$ & $379.00 \pm 3.61$ & $27.33 \pm 3.06$ & $10.00 \pm 4.00$ \\
\hline
\end{tabular}

The total phenolic contents of C. pulcherrima and D. regia contained in embryo, endosperm and seed coat were significant different depending on types of tissues and species. This finding is corresponded to the report of phenolic contents found in embryo, cotyledon and seed coat extracts of nine soybean varieties [9] and the report of phenolic contents found in sweet and sour tamarind seed coat [10]. In both $C$. pulcherrima and D. regia, seed coat extract had the highest antioxidant activity but contained small level of the phenolic contents. This phenomenon was also found in the leave extract of Coleus amboinicus (Lour.) Spreng [11]. These plants may contain a few phenolic content while had other main substances having a high antioxidant activity, such as triterpenes (e.g. euscaphic acid, urxolic acid and oleic acid), monoterpenes (e.g. limonene, ß-phellandrene, sabinene, limonene, biocyclogermacrene), flavonoids (e.g. quercertin) $[12,13]$.
Free radical scavenging activity. DPPH $(1,1$ diphenyl 2 , picryl hydrazyl) method is the most widely reported method for screening of antioxidant activity of plant extract. This assay method is based on the reduction of methanolic solution of colored free radical DPPH by free radical scavenger. The procedure involves measurement of decrease in absorbance of DPPH at its absorption maximum of $517 \mathrm{~nm}$, which is proportional to concentration of free radical scavenger added to DPPH reagent solution $[9,10]$.

In table 2 shows that the percentage of DPPH scavenging activity of seed coat extracts $(100-1000 \mu \mathrm{g} / \mathrm{ml})$ of $C$. pulcherrima (8.68 to 76.16 ) and D. regia (2.69 to 9.63) were higher than those of endosperm and embryo extracts. In addition, the percentage of DPPH scavenging activity of seed coat extracts of C. pulcherrima was statistically significant higher than D. regia. Moreover, embryo and endosperm extracts of C. pulcherrima and D. regia were not significantly 
different. Aadditionally, the percentage of DPPH scavenging concentrations of the extracts. activity was predominately increased corresponded to the

Table 2 The percentage of DPPH inhibition of embryo, endosperm and seed coat extracts between Caesalpinia pulcherrima and Delonix regia

\begin{tabular}{|c|c|c|c|c|c|c|}
\hline \multirow{2}{*}{$\begin{array}{c}\text { Conc. } \\
(\mu \mathrm{g} / \mathrm{ml})\end{array}$} & \multicolumn{2}{|c|}{ Caesalpinia pulcherrima $(\mu \mathrm{g}$ of gallic acid) } & \multicolumn{3}{c|}{ Delonix regia $(\mu \mathrm{g}$ of gallic acid) } \\
\cline { 2 - 7 } & Embryo & Endosperm & Seed coat & Embryo & Endosperm & Seed coat \\
\hline 100 & $1.89 \pm 2.22$ & $2.18 \pm 2.51$ & $8.68 \pm 1.93$ & $0.90 \pm 0.52$ & $0.90 \pm 0.52$ & $2.69 \pm 2.08$ \\
\hline 200 & $3.40 \pm 2.44$ & $3.25 \pm 2.12$ & $17.89 \pm 4.07$ & $3.19 \pm 2.76$ & $2.18 \pm 2.50$ & $4.17 \pm 3.17$ \\
\hline 400 & $4.90 \pm 0.39$ & $5.46 \pm 0.76$ & $34.45 \pm 2.82$ & $5.14 \pm 2.35$ & $2.91 \pm 2.90$ & $6.52 \pm 2.09$ \\
\hline 1,000 & $7.70 \pm 1.40$ & $8.26 \pm 1.26$ & $76.16 \pm 2.49$ & $8.26 \pm 1.26$ & $4.85 \pm 3.28$ & $9.63 \pm 0.60$ \\
\hline
\end{tabular}

The $50 \%$ DPPH radical $\left(\mathrm{IC}_{50}\right)$ of seed coat, endosperm and embryo extracts of C. pulcherrima was $620.33 \mu \mathrm{g} / \mathrm{ml}$, $7264.61 \mu \mathrm{g} / \mathrm{ml}$ and $7876.08 \mu \mathrm{g} / \mathrm{ml}$, consequently. The $50 \%$ $\mathrm{DPPH}$ radical $\left(\mathrm{IC}_{50}\right)$ of seed coat, embryo and endosperm extracts of $D$. regia was $6393.97 \mu \mathrm{g} / \mathrm{ml}, 6497.97 \mu \mathrm{g} / \mathrm{ml}$ and $12237.68 \mu \mathrm{g} / \mathrm{ml}$, respectively. In addition, $\mathrm{IC}_{50}$ of the extracts from both plants were higher than ascorbic acid $(82.37 \mu \mathrm{g} / \mathrm{ml})$ as from tamarind extract [10].

The correlation between the phenolic contents and the percentage of free radical scavenging activity show the antioxidant or anticancer phenomenon. This correlation also reported by others $[10,11,14]$. Furthermore, the amount of phenolic compounds and the percent DPPH scavenging were dose dependent $[10,15]$.

\section{Conclusions}

A few previous investigators have studies the antioxidant activity of $C$. pulcherrima and $D$. regia seed whereas no data has reported the difference antioxidant activity between embryo, endosperm and seed coat extracts from both species. This study is to observe primarily the difference antioxidant activity of both $C$. pulcherrima and D. regia. Our results can be summarized that (1) the highest phenolic contents were found in embryo extract, (2) the seed coat extract of $C$. pulcherrima had the highest antioxidant activity (3) phenolic contents and antioxidant activity of seed coat extracts of $C$. pulcherrima were significantly higher than $D$. regia, and (4) the total contents of phenolic compounds and the percent
DPPH scavenging activity were depended on types of tissues and species.

\section{Acknowledgements}

This work was supported by Faculty of Allied Health Sciences and Faculty of Engineering, Burapha University.

\section{References}

[1] K. Bagchi and S. Puri: East. Med. Health J. Vol. 4 (1998), p.350-360.

[2] I. Jahan, M.S. Rahman, M.Z. Rahman, M.A. Kaisar, M.S. Islam , A. Wahab and M.A. Rashid: Acta Pharm. Vol. 60 (2010), p. 207 -215.

[3] V.D. Shewale, T.A. Deshmukh, L.S. Patil and V.R. Patil: Adv. Pharm. Sci. Vol. 2012 (2012), p.1-4.

[4] V. Sharma and G.P. Rajani: In. J. Pharm. Vol. 43 (2011), p. 168 -171.

[5] M. Sudhakar, Ch.V. Rao, P.M. Rao, D.B. Raju and Y. Venkateswarlu: Fitoterpia Vol. 77 (2006), p. 378 -380.

[6] L.C. Chiang, W. Chiang, M.C. Liu and C.C. Lin: J. Anti. Chemicrob. Chemother. Vol. 52 (2003), p. 194-198.

[7] K. Slinkard, V.L. Singleton: Am. J. Eno. Vit. Vol. 28 (1997), p.49-55.

[8] M.S. Blois: Nature Vol. 181 (1958), p.1199-1200.

[9] J.A. Kim, W.S. Jung, S.C. Chun and C.Y. Yu: Eur. Food Res. Technol. Vol. 224 (2006), p. 259-270.

[10] W. Sittikijyothin and D. Cherdwongcharoensuk: Burapha Sci. J. Vol.16 (2011), p. 47-55.

[11] R. Kaewamatawong and Z. Jounmunkong: J. Ubon Rajathanee U. Vol. 8 (2006), p. 76-88.

[12] N.R. Azevedo, I.F.P. Campos, H.D. Ferreira and T.A. Portes: Phytochem. Vol. 57 (2001), p. 733-736.

[13] C.H. Brieskorn and W. Riedel: Arch. Pharm. (Weinheim) Vol. 310 (1977), p. 910-916.

[14] Y. Sudjaroen, R. Haubner, G. W"urtele, W.E. Hull, G. Erben, B. Spiegelhalder, S. Changbumrung, H. Bartsch, R.W. Owen: Food Chem. Toxicol. Vol. 43 (2005), p. 1673-1682.

[15] C. Saengkhae, W. Arunnopparat, P. Sungkhajorn: Thai. J. Physiol. Sci. Vol. 20, (2007), p.70-78. 